\title{
Structured affordances in the use of open-ended tasks to facilitate collaborative problem solving
}

\author{
Man Ching Esther Chan \\ David Clarke \\ International Centre for Classroom Research, Melbourne Graduate School of \\ Education, Level 3, Queensberry Street, The University of Melbourne, VIC 3010, \\ Australia \\ Phone: +613 83441234 \\ mc.chan@unimelb.edu.au
}




\begin{abstract}
Contemporary curriculum demands the development of both problem solving skills and negotiative skills required for collaborative group work. Tasks are required that create the best possible conditions for students to develop both of these skill sets. Open-ended tasks have been shown to provide these conditions, but they also require the teacher to relinquish some level of control over student activity, since the open-endedness of the tasks provides students with the opportunity to realize their intentions rather than just the teacher's. It is necessary to investigate the nature of the affordances created by the use of open-ended tasks in order to anticipate how they might best be used for both instruction and learning. What is needed is a structured way to identify the affordances offered by open-ended tasks. This paper reports a study conducted in a laboratory classroom equipped to record classroom social interactions in great detail using advanced video technology. The reported analysis addresses the following question: What are the foci of the students' social interactions during collaborative problem solving while attempting open-ended mathematical tasks? Analysis was carried out in relation to each type of data generated: written response, transcripts and videos. Our research has identified structures to represent these affordances so that teachers can both anticipate them and draw on them in monitoring and facilitating student collaborative problem solving. The structured identification of affordances in relation to (a) written product and (b) negotiative focus provides teachers with two frameworks by which to scaffold student collaborative work while attempting open-ended tasks.
\end{abstract}

\title{
Keywords
}

Open-ended tasks, classroom research, social negotiation, collaborative problem solving 


\section{Introduction}

Contemporary curriculum demands the development of both problem solving skills and negotiative skills required for collaborative group work. Around the 1980s, team-based problem solving received significant attention in mathematics education, particularly in the United States and in Australia, where governments and curriculum and teaching standards strongly encouraged the use of small group work in mathematics classrooms (Goos and Galbraith 1996; Webb 1991). In the 21 st century, small group work in mathematics continues to be a prominent teaching approach in many Western countries, with advocates arguing, among other reasons, for its effectiveness for addressing achievement gaps among minority groups (e.g., CREA 2012). Outside of mathematics education, teambased problem solving appears to have changed from being seen as a means to an end (i.e., a teaching strategy aimed at the improvement of student achievement; see Capar and Tarim 2015; Thomas and Higbee 1996), to now becoming "a crucial and necessary skill across educational settings and workforce" (OECD 2013b, p. 3).

Mathematical tasks provide a crucial prompt for facilitating learning and communication in the mathematics classroom (Stein and Lane 1996; Sullivan et al. 2000; Viseu and Oliveira 2012). Teachers can adjust key features of the task, depending on the intended learning objective, the target mathematical content, and the range of student abilities (Sullivan and Clarke 1991). Open-ended tasks, in particular, have been found to be powerful for creating opportunities for student exploration, collaboration, and sophisticated mathematical reasoning (Kosyvas 2016). However, the open-endedness of tasks can also lead to a reduction in the mathematical relevance of the participants' learning activity when teachers partially relinquish their control over the form of the students' responses, allowing students the freedom to explore and possibly become sidetracked (Inoue and Buczynski 2011; Wu 1994). Nonetheless, open-ended mathematical tasks also offer students a greater opportunity to exercise metacognitive skills related to tool selection and decision making. When used as the basis for collaborative group work, they also create conditions conducive to the use and development of negotiative skills. 
This paper reports research into the social interactions that occur as students engage in collaborative problem solving while attempting open-ended mathematics tasks, taking the social negotiation of meaning as a key constitutive element of learning (Clarke 2001a). The two goals that prompted the research use of open-ended tasks in this study relate to the creation of optimal conditions for the occurrence of 1) productive negotiative exchange and 2) mathematically sophisticated activity.

Given concerns over the devolution of control from teacher to student arising from the use of open-ended tasks, it becomes imperative to develop strategies to investigate the various foci of students' attention when engaged in collaborative problem solving. This research specifically focused on the different considerations to which students attend as they attempt the tasks. Some of these considerations can be inferred from characteristics of the students' written problem solving attempts, so this study also examined student written material. The paper addresses the following question: What are the foci of the students' social interactions during collaborative problem solving when attempting openended mathematical tasks? The reported analysis offers a window into student engagement with open-ended tasks during collaborative problem solving.

\section{Literature review}

\subsection{The importance of collaborative problem solving: a combination of two prioritized skill sets}

Collaborative problem solving combines two skill sets, namely, problem solving skills and negotiative skills. Problem solving can be defined as "the process of applying previously acquired knowledge to new and unfamiliar situations" (Chambers 1978, p. 67). The process is seen not only as central to the learning of mathematics and mathematical thinking (Clarke et al. 2007; Pólya 1971; Stacey 2005), but also essential in other discipline areas, such as Science, Technology, Engineering, and Medicine (Hummers-Pradier et al. 2010; Pazos et al. 2010). Problem solving is viewed as the hallmark of human cognition (Langley and Trivedi 2013; Newell and Simon 1972) and extends to all aspects of everyday living (OECD, 2013a). However, with technological advancement, increase in automation in industries, and globalization (Schuster et al. 2015), being able to 
solve problems individually is no longer seen as sufficient to meet the needs of the 21 st century.

Team-based problem solving is increasingly recognized as essential for effective functioning in the 21 st century society (Griffin et al. 2012; National Research Council 2011). Businesses and industries around the globe place high value on teamwork, interpersonal skills, and problem solving skills in their employees as the job market continues to phase out routine-based tasks through automation and digitization (Deming 2015; World Economic Forum 2014). At the same time as the job market demands these collaborative problem solving skills, education systems in different parts of the world promote problem-based and collaborative learning as a means for more effective student learning (HmeloSilver et al. 2013). The advocacy of collaborative problem solving activity in mathematics classrooms finds support both as an effective instructional practice and as one aspect of sophisticated mathematical thinking requiring purposeful promotion and development.

\subsection{Open-ended tasks: creating optimal conditions for collaborative problem solving}

Task design can form an important part of lesson planning, especially for mathematics teachers (Choy 2016; Roche et al. 2014). In the case of collaborative problem solving in the classroom, tasks are needed that create the best possible conditions for students to develop both problem solving skills and negotiative skills required for collaborative group work. Open-ended tasks have been shown to provide these conditions (Kosyvas 2016), but they also require the teacher to relinquish some level of control over student activity, since the open-endedness of the tasks provides students with the opportunity to realize their intentions rather than just the teacher's (Sullivan et al. 2015). With the current curriculum emphasis on collaborative problem solving, there is a need to identify the affordances of open-ended tasks for both instruction and learning in the area of collaborative problem solving in mathematics.

It has been argued that whether or not a task is experienced as open-ended is ultimately a consequence of the individuals' previous educational history, the expectations of the teacher, and the students' understanding of these (Brousseau 1986). The open-endedness of tasks has been classified in terms of three areas: 1) 
the number of correct ways to solve the problem addressed in the task; 2) the number of possible correct solutions; and 3) the possibility of developing the task further by changing the attributes or conditions of the original task (Nohda 2000).

However, Clarke (2011) argued that open-ended tasks are difficult to define due to the dependence of task interpretation on the social situation in which the task is framed and undertaken. A task that allows for multiple answers could be interpreted by the respondent as a closed task if one answer is explicitly accorded higher value than another (as in an assessment context). On the other hand, any task can be considered as "open-ended" if its open-endedness resides in the possibility of multiple solution pathways, due to the idiosyncratic nature of student thinking (see, for example, Marriot 1976). From this point of view, the open-endedness of a task is situation dependent and it is only through the implementation of the task that its open-ended potential is realized.

In terms of teaching, a key consideration in instructional planning and task design is the balance between the promotion of student agency and mathematical decision-making and the achievement of more content-related curricular goals. In the contemporary educational climate, there are strong calls for the development of skills such as communication, argumentation, collaboration and critical thinking, which are highly valued by contemporary employers (Collet and Hine 2010; Office of the Chief Scientist 2014) as being associated with effective teambased problem solving activity (Binkley et al. 2012; OECD 2013b). However, a teacher seeking to promote the development of such skills through the use of open-ended tasks runs the risk that the students can become sidetracked, and therefore miss out on discussion that could be more meaningful or productive for their learning. A case study (Inoue and Buczynski 2011) of a preservice teacher's use of open-ended questions, for example, observed several "stumbling blocks" (p. 10) in an inquiry mathematics lesson when the learners gave diverse, unexpected responses which the novice teacher was not equipped to utilize in a pedagogically meaningful way.

Although open-ended tasks may afford the possibility of more sophisticated student thinking, affordance is not the same as realization. The provision of the possibility of a mathematically sophisticated general solution does not ensure that a particular student will avail him or herself of that affordance or even recognize its existence. On the other hand, the prescription of a 
level of sophisticated response may deny students the possibility of engaging with the task at a more fundamental level. Such engagement has been shown to lead to an emergent recognition by the student of task affordances that might have discouraged engagement, if encountered prescriptively at the commencement of the task (Williams 2000).

There is a tension between the teacher's instructional intentions (and associated actions) and the students' consequent activity (and ultimate learning). This tension is probably inevitable and even productive. The existence of this tension should reassure us that student agency has not been precluded entirely from our classrooms. (Clarke et al. 2014, p. 140)

Open-ended tasks create the conditions for the development of the sort of communication and reasoning skills listed above (Clarke 2011), but their use poses specific instructional challenges for the teacher, particularly in the area of collaborative problem solving. To a significant extent, these instructional challenges relate to how best to scaffold productive, collaborative student negotiation in the course of task completion. The research reported in this paper investigates student collaborative activity in response to open-ended tasks, under conditions where teacher intervention was deliberately constrained. The specific purpose of the investigation is to understand the nature of student interactions in such situations, particularly with respect to the variation in student response and collaborative behavior afforded by the use of open-ended tasks. Our ultimate intention is to inform teacher scaffolding by providing a structured framework by which the affordances created through the use of open-ended tasks can be recognized and utilized in promoting student collaborative problem solving in mathematics.

\subsection{Social negotiation and collaborative problem solving}

The process of learning can be seen as the construction of knowledge by students through their interaction and participation within the classroom setting. As has been noted repeatedly, this participation and the associated forms of interaction are significantly determined by the tasks employed (Shimizu et al. 2010). Lave and Wenger (1991) asserted that "participation is always based on situated negotiation and renegotiation of meaning in the world" (p. 52). As legitimate sites 
of situated mathematical practice, classrooms provide settings in which these negotiative processes can be recorded and analyzed. Contemporary social theories of learning accord a central role to the situated construction of shared meaning, through such constructs as "the didactic contract" (Brousseau 1986) and "sociomathematical norms" (Yackel and Cobb 1996).

Brousseau and colleagues (Brousseau 1986; Brousseau et al. 2014) conceptualized the didactic contract as follows:

[A]n interpretation of the commitments, the expectations, the beliefs, the means, the results, and the penalties envisaged by one of the protagonists of a didactical situation (student, teacher, parents, society) for him- or herself and for each of the others, à propos of the mathematical knowledge being taught. (Brousseau et al. 2014, p. 154)

According to Brousseau and his colleagues, it is when the contract is being broken (e.g., the teacher or the student acts in an unexpected way) that the specific conditions and processes of the contract are most visible. By its nature, a task intended by the teacher to be open-ended is less prescriptive than a deliberately closed task regarding the specific mathematical activity it might provoke. Since it is the teacher's intentions that are the immediate focus of this discussion, we use the terms "open" and "closed" to reflect the instructional intentions of task use. Given this task distinction, the terms of the didactic contract for an open task are likely to require more explicit discussion and, possibly, negotiation than would be required for a closed task. The students' recognition of the affordances of the task's intended open-endedness will be pivotal to any discussion of revisions to the didactic contract. This dynamic between teacher intention and student intention/interpretation is central to the socially negotiated nature of student taskbased activity.

Yackel and Cobb (1996) advanced the notion of sociomathematical norms by investigating particular regularities in the social interactions within the mathematics classrooms. They suggested that individuals develop their personal understandings of the social interactions in the mathematics classroom as they participate in the negotiation of classroom norms, some of which are specific to mathematics. Examples of sociomathematical norms include the following: what counts as mathematically different, mathematically sophisticated, mathematically efficient, mathematically elegant, and what is considered to be an acceptable 
mathematical explanation and justification. Such norms are distinguished from mathematical procedures or mathematical correctness (mathematical norms), while also distinct from social norms that are applicable to general classroom practice and call upon tenets of behavior in the broader community. According to Yackel and Cobb, "what becomes mathematically normative in a classroom is constrained by the current goals, beliefs, suppositions, and assumptions of the classroom participants" (p. 460), and such goals and implicit understandings are influenced by what is legitimized as acceptable mathematical activity in the classroom. The didactic contract and sociomathematical norms highlight the significance and mutuality of student and teacher expectations regarding classroom activity and the need for negotiation any time a new task type challenges the established norms. In this paper, our primary interest is in the role of open-ended tasks in creating conditions conducive to collaborative problem solving, the investigation of the negotiative aspects of such student collaborative activity, and the identification of structures inherent in the affordances arising from the use of such tasks.

\section{Conceptualizing this study}

As stated in the introduction, the function of mathematical tasks in this research is a central one, both in their potential to provide conditions conducive to studying student collaborative problem solving, and as the embodiment of the sophisticated performances that are the goal of the contemporary mathematics classroom. In terms of research design, studies of social interaction in settings characterized by collaborative problem solving have typically constrained the social complexity of the situation by using clinical designs focusing on the interactions of individual dyads, frequently triggered by digitally-delivered problems (e.g., Olive and Steffe 1990; Steffe and Wiegel 1994). Other attempts to seek structure in the diversity of social interactions have included comparative studies, in which aspects of instructional setting, culture, and social interactive norms can provide the variation needed to reveal underlying structure or consistency of pattern (e.g., Clarke et al. 2006). The first approach (clinical designs) compromises validity in the interest of experimental control. The second (comparative studies) relinquishes control over key variables in an attempt to capture social interaction in naturally occurring settings. The tension between the need for control in an 
experimental environment and the freedom needed for the participants to interact and behave as they would in a naturalistic classroom setting remains a challenge in the design of research studies investigating student learning in social settings.

The recent development of a laboratory classroom at the University of Melbourne has made possible research designs that combine better approximation to natural social settings. The retention of some control over crucial aspects of setting, individual attributes deployed, task characteristics, and possible forms of social interaction, makes possible conclusions about connections between interactive patterns of social negotiation and problem solving and knowledge products (learning). As a result these possibly causal connections can be identified with greater confidence. The Social Unit of Learning project used the Science of Learning Research Classroom (SLRC) at the University of Melbourne to examine individual, dyadic, small group (four to six students) and whole class problem solving and learning in mathematics. The SLRC uses advanced video technology to capture classroom social interactions with a rich amount of detail. The facility was purposefully designed and built to allow simultaneous and continuous documentation of classroom interactions using multiple cameras and microphones (see https://pursuit.unimelb.edu.au/articles/high-tech-classroom-sheds-light-onhow-students-learn).

The project collected multiple forms of data for analysis including student written products and high definition video and audio recordings of the actions (particularly the utterances) of every student and the teacher in the classroom. This multiplicity of data sources allows for cross-examination of data from multiple perspectives by multiple researchers (Clarke et al. 2012). The analysis reported in this paper addresses the following research question:

What are the foci of student social interactions during collaborative problem solving while completing open-ended mathematical tasks in this project?

This question provided an entry point for the identification of the affordances arising from the use of such open-ended tasks. 


\section{Research design}

The laboratory classroom is equipped with 10 built-in video cameras and up to 32 audio channels. Intact Year 7 classes from an outer suburban secondary school in the state of Victoria were recruited with their usual teacher in order to exploit existing student-student and teacher-student interactive norms. Ethics clearance was obtained from the university and all participating students, their caregivers, and the participating teachers provided their consent to be involved in the study. Two classes of Year 7 students (12 to 13 years old; in total 50 students) provide the focus for this report. At the time of the study, both the Australian national curriculum (Australian Curriculum Assessment and Reporting Authority 2015) and the curriculum in the state of Victoria, made explicit in the following expectations:

The curriculum anticipates that schools will ensure all students benefit from access to the power of mathematical reasoning and learn to apply their mathematical understanding creatively and efficiently... [and] encourages teachers to help students become self-motivated, confident learners through inquiry and active participation in challenging and engaging experiences. (Victorian Curriculum Assessment Authority 2016) The students came from a school in which attempts were being made to teach inquiry and collaborative skills, although, according to the students' teachers, the students were not familiar with the kinds of open-ended tasks used in the study. The content relevant to each task was judged by the teacher to be appropriate and consistent with the mathematics curriculum at that year level. Each class participated in a 60-minute session in the laboratory classroom involving three separate problem solving tasks that required them to produce written solutions. Problem solving, in this sense, simply means "the process of applying previously acquired knowledge to new and unfamiliar situations" (Chambers 1978, p. 67), and does not specify the degree of open-endedness of the tasks.

\subsection{Problem solving tasks}

The problem solving tasks used in the project were drawn from previous research (e.g., Clarke 1996; Clarke and Sullivan 1990, 1992; Sullivan and Clarke 1988, 1991, 1992). All three tasks had multiple possible solutions, included symbolic or graphical elements, and afforded connection to contexts outside the classroom, 
although as mentioned earlier, the open-endedness of the tasks could be ascertained only in their implementation when examining the student interactions and solutions. Nonetheless, the task features were intended to make the thinking and/or social processes of the problem solving activity more visible, as the students could express their thinking through multiple modes (e.g., verbal, graphical, textual, etc.) and approach the task using different strategies, or prioritize different forms of knowledge or experience. The content foci of the three tasks were deliberately selected to be disconnected to avoid conceptual carry-over effects between tasks.

Task 1 provided students with a graph with no labels (Figure 1) with the following instructions: "What might this be a graph of? Label your graph appropriately. What information is contained in your graph? Write a paragraph to describe your graph."

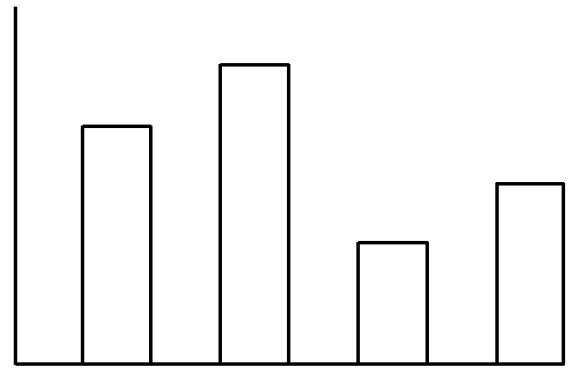

Figure 1. Task 1 stimuli.

Task 2 was specified as follows: "The average age of five people living in a house is 25 . One of the five people is a Year 7 student. What are the ages of the other four people and how are the five people in the house related? Write a paragraph explaining your answer."

Task 3 stated that "Fred's apartment has five rooms. The total area is 60 square metres. Draw a plan of Fred's apartment. Label each room, and show the dimensions (length and width) of all rooms."

The students attempted the first task individually (10 minutes), the second task in pairs (15 minutes), and the third task in groups of four to six students (20 minutes). Figure 2 illustrates the grouping for the three tasks for a single group of students.

The focus of this paper is on the affordances of open-ended tasks to create conditions conducive to both student collaborative group work and to the investigation of student collaborative group work. This focus addresses the distinctive features of group work, and the connection of these to the nature and 
function of the open-ended tasks. These features are most evident in the data set arising from the completion of Task 3.

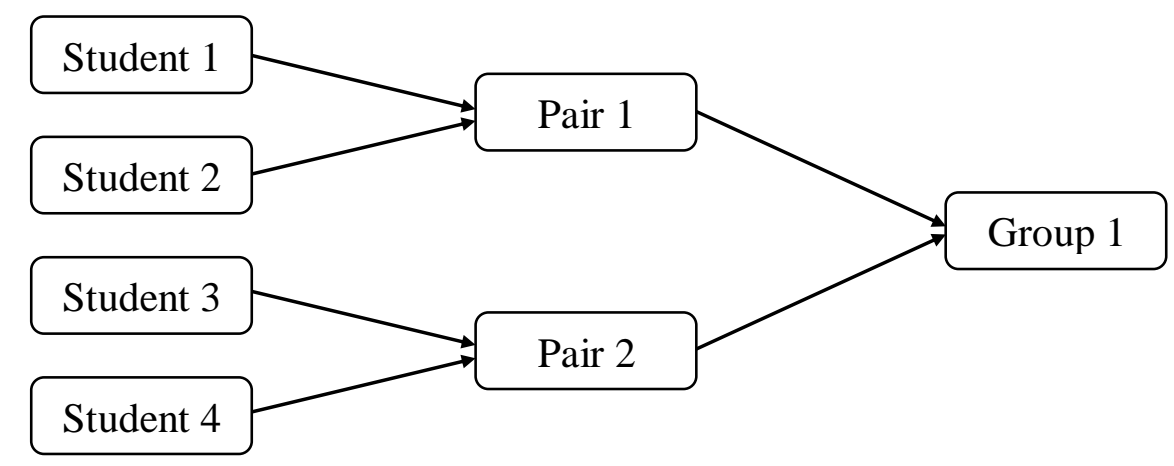

Task 1

Individual work
Task 2

Pair work
Task 3

Small group work

Figure 2. Student grouping for the three tasks.

Individual task completion for Task 1 provided some evidence of each student's sensitivity to the affordances offered by open-ended tasks and Task 2 completion by pairs provided some data indicative of students' inclinations and expertise in collaborative activity. The focus of this report, however, is on the collaborative activities of the students during the small group work (Task 3 ), in which the students were obliged to work as a team.

To minimize the effect of the teacher on the students' interpretation of the tasks, the teacher was given very specific directions with regard to the stimulus to be provided to students. Evaluative comments were to be avoided and very precise limitations were placed on possible teacher assistance to students. The teacher could respond to questions seeking clarification, but was asked to avoid giving direct instruction or directions regarding task completion. Consistent with the two goals identified earlier (negotiative exchange and mathematical sophistication), the major focus of teacher input was to encourage negotiative exchange among students and student consideration of what might constitute "a complete answer" to the stated problem.

Having established the activity structure (see Figure 2), the next section reports each stage of the analysis. We have chosen to report the findings of each stage immediately following the outline of the analytical methods employed at that stage. We consider that this juxtaposition of methods and findings allows the connection between the analytical method and the consequent findings to be better understood, thereby conferring greater credibility on the findings. 


\section{Analyses and findings}

The overarching purpose of the analyses reported in this paper is the identification of regularities in the negotiative interactions of students engaged in collaborative problem solving when attempting open-ended mathematical tasks. The richness and complexity of the data afford a variety of analytical approaches and these are reported as three analytical stages, together with the findings arising at each stage. Stage One: The examination of the student written solutions constituted the first step in the analytical process. Stage Two: Transcripts and video records were analyzed after the analysis of the group's written solutions had been completed as thoroughly as possible. The analysis of the written solutions provided an indication of whether the mathematical options afforded by the open-endedness of the task were recognized and put into effect by the students. The result of this analysis was used to determine the choice of which student groups to analyze in stage two (transcript analysis). Stage Three: The interpretive accounts constructed from the analysis of the students' written solutions and of the transcripts of student speech during the collaborative activity were compared with the corresponding sections of the video record to determine their interpretive validity (consistency with the students' observable behaviors).

\subsection{Analysis of the written products}

As mentioned, the "open-endedness" of a task can be considered from the perspective of the individuals' previous educational history, the expectations of the teacher, and the students' understanding of these (Brousseau 1986). In the case of the tasks employed in this study, the researchers' intention was that the tasks be interpreted by the students as sufficiently open to require negotiation and the teachers were briefed on this aspect of the tasks' selection. Whether the students recognized the options available for their negotiation was something that varied from student to student and group to group. It was only through the implementation of each task with a particular student or student group that its open-ended potential could be seen to be realized or not. Nonetheless, the affordance of choice regarding method and acceptable solution was intended to be a feature of each task. The students' written solutions were first examined to determine the level of open-endedness as perceived by the students. Figure 3 
shows the 12 group solutions to Task 3 as an illustration of the variety of solutions produced by the students.

Group 1-1

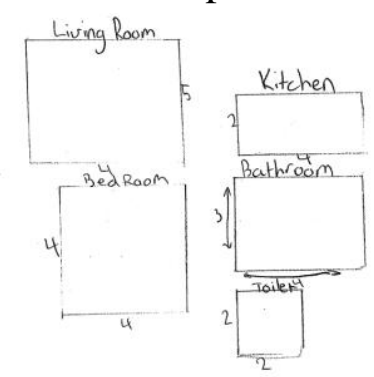

Group 1-4

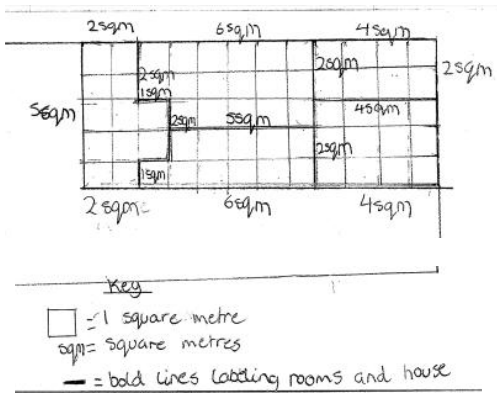

Group 2-1

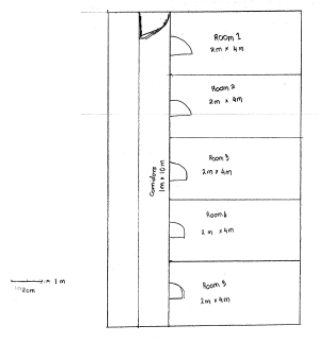

Group 2-4

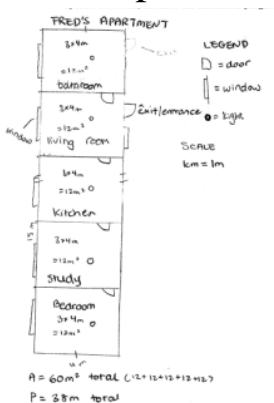

Group 1-2

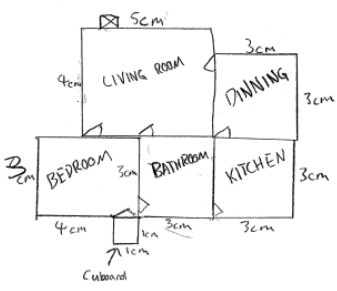

Group 1-5

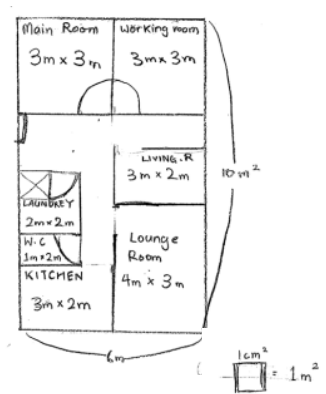

Group 2-2

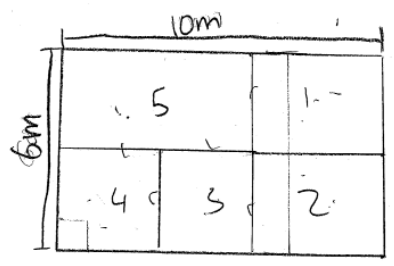

Group 2-5

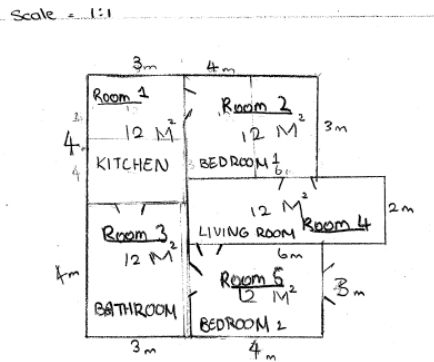

Group 1-3

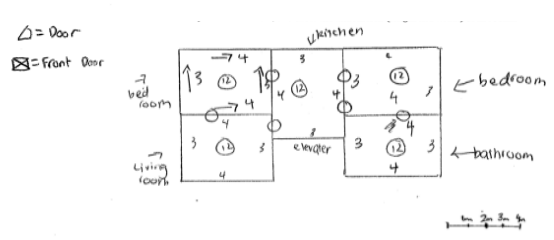

Group 1-6

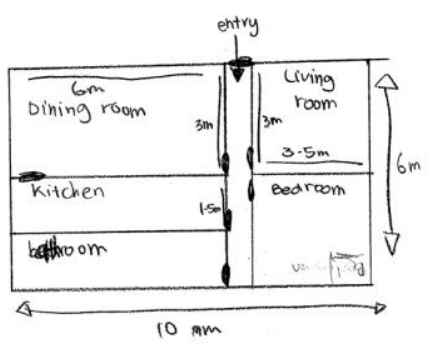

Group 2-3

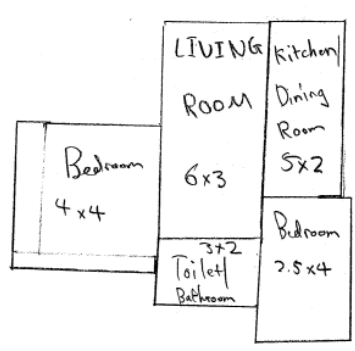

Group 2-6

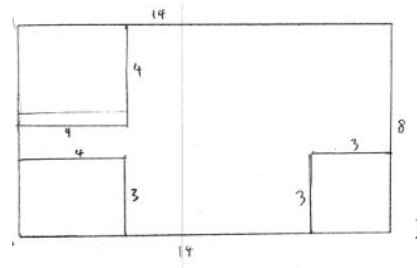

Figure 3. Student group solutions to Task 3.

As can be seen, the students produced a variety of responses. The working out sheets from the students also suggested that students tried various alternative solutions before reaching their final solution. After reviewing all of the written solutions of the three tasks for all of the 50 students, a classificatory framework 
was formulated that could be used to distinguish responses to all three tasks in ways hypothesized to be reflective of differences in the students' underlying thought processes:

(i) Problem solving approach primarily shaped by the mathematics or by the context or attentive to both conditions;

(ii) Holistic or reductionist approaches to problem solution;

(iii) Highly specific, multiple or generalized written answers;

(iv) Highly textual, graphic and/or symbolic/numerical solutions.

Figures 4 and 5 provide examples of two contrasting written solutions to the task. The first one (Figure 4) was submitted by Aruna (female), Natalie (female), Michael (male), and Daniel (male) (Group 1-1), and the second one (Figure 5) was by Anna (female), Pandit (female), John (male), and Arman (male) (Group 1-5). Both solutions provided an apartment plan with an area that added up to 60 square meters, matching the task specification.

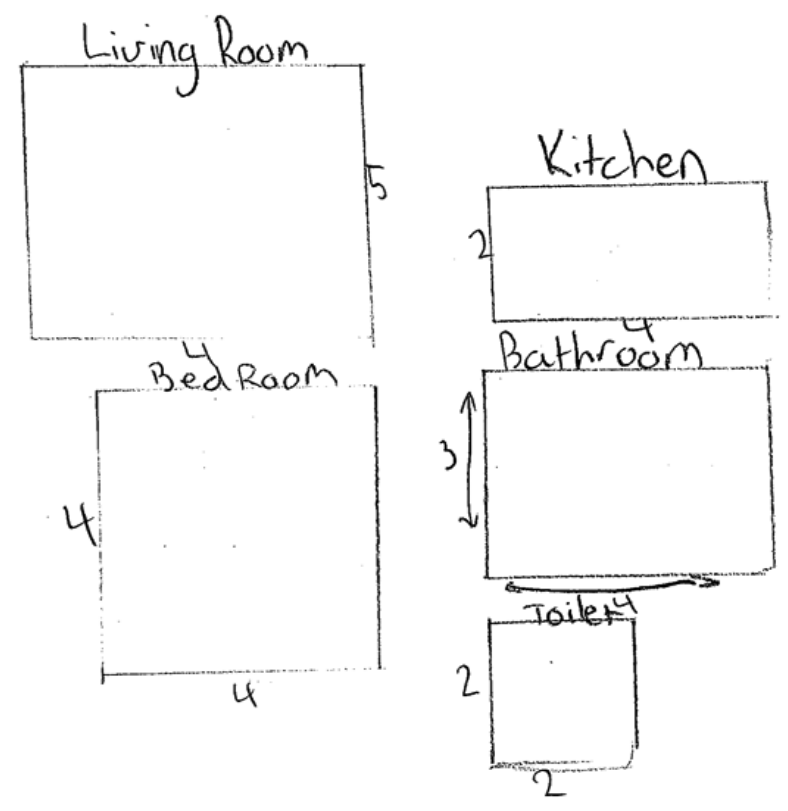

Figure 4. Group 1-1 solution to Task 3.

The written solution of Group 1-1 (Figure 4) appears to be reductionist, with students starting from the possible attributes of the five constituent rooms considered entirely separately. This plan highlights the features of individual rooms rather than their configuration and rationality as functional components of the apartment as a whole. The disconnected rooms are clearly labeled, but without additional features (e.g., doorways or a scale). 


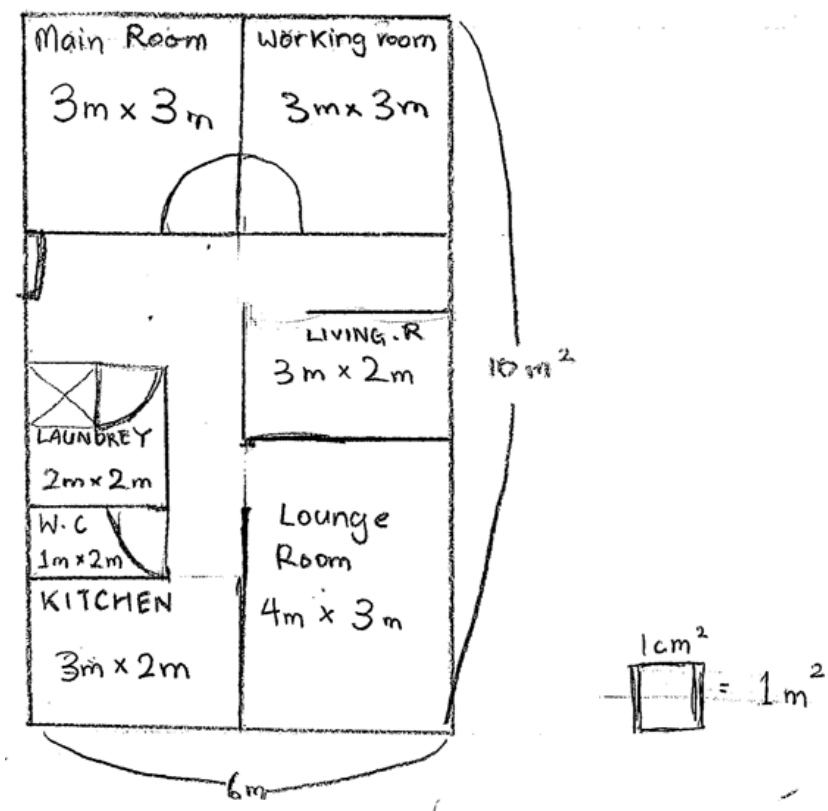

Figure 5. The group solution to Task 3 produced by Anna, Pandit, John, and Arman.

In contrast, the solution (Figure 5) by Anna, Pandit, John, and Arman appears to be holistic, in so far as the students took a possible "footprint" of the apartment as a whole as their starting point and then partitioned that footprint consistent with the demands of the task. Employing this more holistic approach, the rooms are integrated within the plan, with connecting corridors and adjoining walls. The rooms and dimensions are clearly labeled with a scale provided.

It should be noted that this second approach immediately requires the group to address the question of how corridors are to be accommodated within the task conditions. In the more reductionist approach adopted by Group 1-1, this is not so imperative. Both approaches are potentially of interest, but the approach of the second group offered more negotiative opportunities and provided richer and more diverse negotiative examples.

Since our interest is in negotiation within collaborative problem solving, possibilities of choice are intrinsically of interest. Each such choice arose only because of inherent affordances in the chosen tasks. If no choices are afforded, then there is little to negotiate. Indeed, in some cases, classroom norms of practice were such that the negotiative potential of an afforded choice was not realized. For example, if the student's classroom experience included only tasks with a single correct solution, the possibility of multiple or general solutions might go unrecognized and therefore unrealized as a matter for negotiation and choice. 
Rather than assuming that certain features are more desirable ("better") than others (e.g., holistic vs. reductionist; or shaped by mathematics vs. shaped by context), the four characteristics provide a way to describe and differentiate the different written solutions and to identify evidence of social negotiation. Our approach was not intended to privilege particular solution approaches, but to identify particular cases where the data made visible a range of mathematically significant choices negotiated by the collaborating students.

\subsection{Analysis of the transcript data}

Our main interest was the documentation of the social interactions that characterized the participation of students in collaborative problem solving, and the identification of task elements conducive to such participation. The analysis reported next draws upon the transcripts of the video record in order to connect the written products to the generative student negotiative interactions. Analysis of the transcripts employed the negotiative event as the unit of analysis (Clarke 2001b). In this analysis, a negotiative event is defined as "an utterance sequence constituting a social interaction with a single identifiable purpose." Data relating to the third task provided the focus of this analysis.

Analysis of the transcripts of student-student interactions within both pair work and group work identified three qualitatively distinct foci of interaction, which in combination accounted for all negotiative events, and which we have characterized as follows:

- Mathematical: Mathematical facts and procedures required for completion of the task;

- Sociomathematical: Norms related to forms of acceptable solution and the reciprocal obligations of teacher and students in problem solution;

- Social (all other social interactions): Obligations, agency, responsibilities and acceptable behavior within the group.

Below are illustrative examples of each of the three foci. These examples are drawn from interactions involving the same students during Task 3 (Anna, Pandit, John, and Arman in Group 1-5). 
Negotiative Event 1. Mathematical

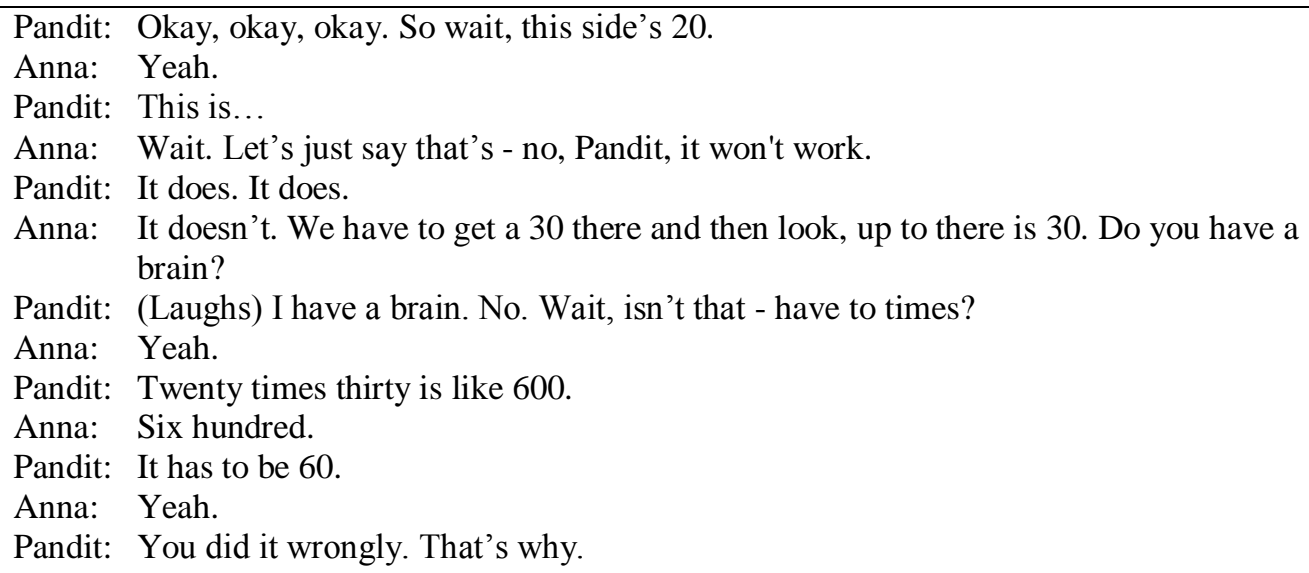

Negotiative Event 2. Sociomathematical

Anna: Guys, let's actually change the scale.

Pandit: We can't.

Anna: Why not?

Pandit: We're not allowed to change.

Anna: You are. Let's make two centimetre square equals one metre.

Pandit: No, don't do that. That's confusing.

Negotiative Event 3. Social (All other social interactions)

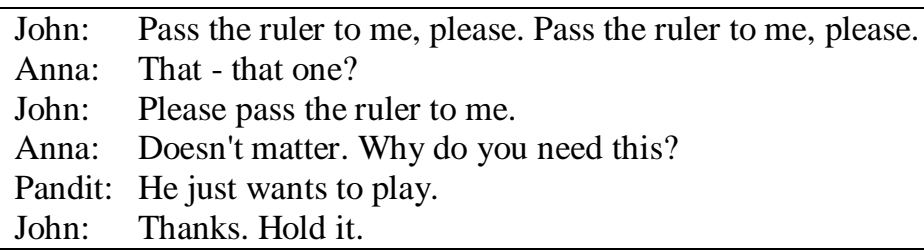

The first negotiative event involves Anna and Pandit realizing that they need to multiply the length and width of the apartment to calculate the total area. Their apartment plan of $20 \mathrm{~m} \times 30 \mathrm{~m}$ had a total area of $600 \mathrm{sqm}$, which was much larger than the 60sqm specified in the task. The focus of the negotiation was on the correctness of the mathematics (Pandit: "You did it wrongly. That's why.").

The second negotiative event involves the students deciding on the scale of their apartment plan. Anna wanted to change the scale from $1 \mathrm{~cm}: 1 \mathrm{~m}$ to $2 \mathrm{~cm}: 1 \mathrm{~m}$. The focus of the interaction was based on the students' perceptions of an acceptable solution (Pandit: "You are not allowed"; Anna: "You are [allowed to]."). The pair were negotiatively revisiting the "rules of engagement" for task 
completion - that is, the sociomathematical norms prescribing what is and is not a permissible approach to task solution.

The third negotiative event involves John requesting a ruler from Anna not to complete the task but to play around with. Anna initially did not understand the reason for John's request and Pandit explained to her John's intention ("He just wants to play [with the ruler]"). The exchange among the group is just one of many social interactions that are neither mathematical nor sociomathematical, but concerned with the purely social functioning of the group.

The three negotiative events illustrate three distinct foci for student-student interaction: mathematical, sociomathematical, and social. Based on analyses conducted, it is our hypothesis that negotiation with respect to each of these employs its own lexicon and appeals to a distinct authority, as follows:

1. Mathematical correctness

2. Classroom norms or conventions of task completion

3. All other social interactions not subsumed in the first two categories. These can address such things as group organization, the sharing of resources, and social obligations and expectations, where these are independent of mathematical considerations.

Mathematical interactions and the negotiation of mathematical meaning not only invoke mathematics terminology, but employ distinctive logical connectives, invoking notions of truth (e.g., "is" and "wrong") and also appeal to utility warrants such as "it works." Sociomathematical negotiations are more likely to be phrased in conditional or relativist terms and involve reference to approval or permission (e.g., "allowed to"). Negotiations of social matters can involve responsibility and expectation (like sociomathematical considerations) but the invoked authority is likely to appeal to moral obligation and also to make more frequent reference to affect. Alternating use of each lexicon within an interactional sequence can be thought of as analogous to the familiar phenomenon of "code-switching" (Prediger et al. 2016) documented in classes of bilingual or multilingual learners. As students shift from one negotiative focus to another, they employ language drawn from the relevant lexicon to express themselves.

The previous excerpts give an impression of relatively clear distinction between the three negotiative foci, but, in practice, all three foci co-exist in an 
entangled form in the negotiative interactions documented in the mathematics classroom. Below is an excerpt that illustrates such entanglement.

Excerpt. Entangled negotiative foci

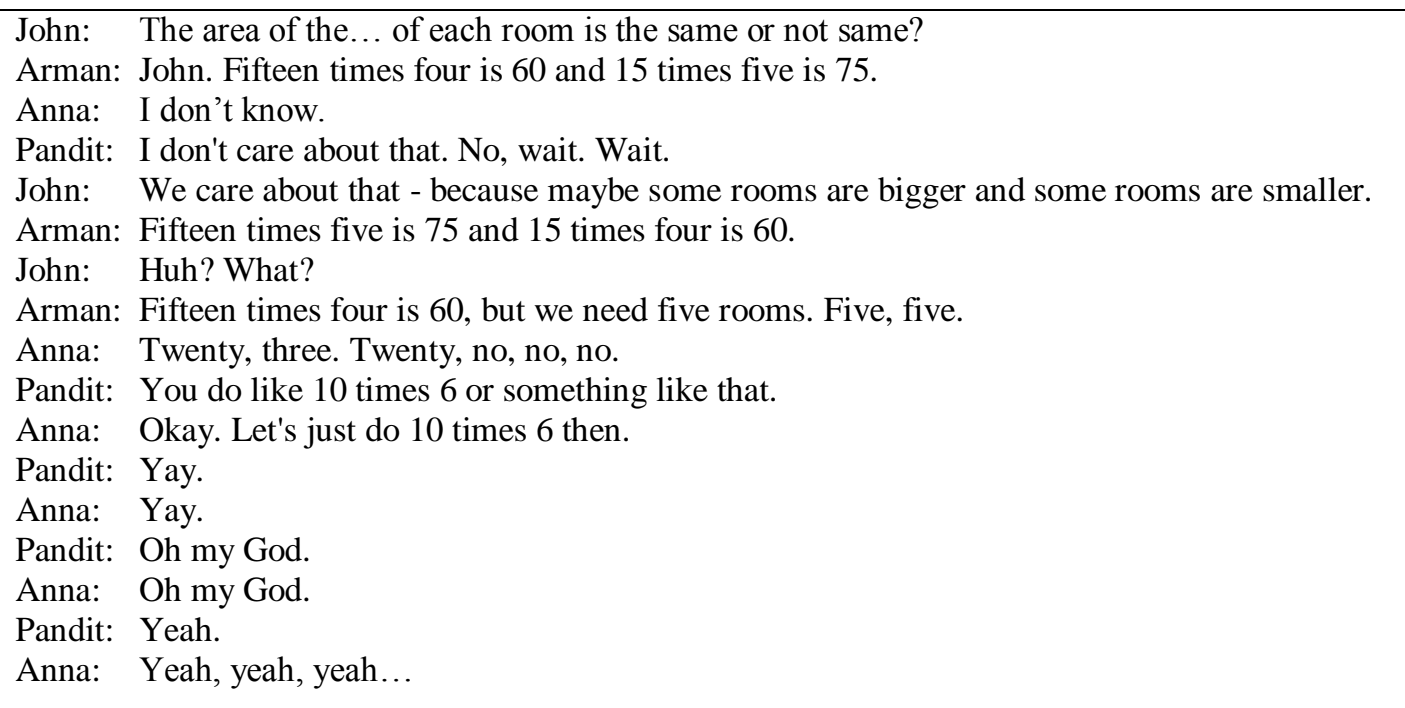

The four students participating in the exchange above had different foci. John was concerned about the task expectations (sociomathematical) in terms of whether the rooms can be of the same size or not. Arman was concerned about John's calculation of the size of each room of 15 sqm which produced an overall size of $75 \mathrm{sqm}$ instead of $60 \mathrm{sqm}$ as specified in the task (mathematical). Neither of the issues raised by Arman nor John were of concern to Anna and Pandit who were focused on working out the overall size of the apartment (mathematical). Anna's parroting of Pandit's utterances towards the end of the excerpt after they reached agreement could either be expressing collegiality or sarcasm towards Pandit (social).

In relation to the unit of analysis, the excerpt can be interpreted as three overlapping negotiative events: one consisting of the interchange between John and Arman focusing on the size of each room; one between Pandit and Anna focusing on the overall size of the apartment; and one concluding exchange between Pandit and Anna that is basically social in focus. Entanglement exists in both the actuality of the overlapping speech (negotiative events) and also in the shifts in focus between one utterance and another. The term "entanglement" also recognizes that each pair (John-Arman and Pandit-Anna) is aware of the actions/statements of the other pair, as indicated by Anna's statement: "I don't 
care" and John's response, "We care about that." The potential exists for the convergence of the separate negotiations into a further negotiative event involving all four students, but this does not occur within the brief transcribed sequence.

\subsection{Analysis of the video data}

At this point, it is also appropriate to ask, "In what way does access to the video record (as distinct from the transcripts) provide additional insight into the studentstudent interactions?" From the excerpts above, there is evidence of discord between Anna and Pandit, while John was trying to become involved in the girl's discussion and Arman was shifting between being involved in the group task and talking to himself. However, it was striking when viewing the video recording, that the interactions between the students appear far less confrontational than might appear from reading only the transcribed verbal interactions. There was frequent laughter between the students and the interactions between Anna and Pandit and interactions within the group appear to have a good humored character, when one takes into consideration the students' body language, facial expression, and tone of voice. The video record also provides important information concerning whether or not interacting pairs of students were aware of each other's actions/statements and whether a silent student was a "silent participant" in a particular negotiation (Remedios et al. 2008) or disconnected from that exchange. An attentive listener and an uninterested non-participant both appear as silences in the transcript. For the interactions that are the focus of this paper, the video analysis provided important additional detail regarding student affect and engagement, the direction of student statements (to whom) and attention (to what), and the enacted connections between student interactions and elements of the written product.

\section{Discussion and Conclusion}

This paper addresses the question: What are the foci of the students' social interactions during collaborative problem solving while completing open-ended mathematical tasks? The analysis sheds light on the affordances of open-ended mathematical tasks for student collaborative problem solving as the students were obliged to verbalize their thinking and visibly enact connections between their thinking and constructed objects (e.g., written task solutions) as part of the 
collaborative process. In particular, our analysis identifies written response characteristics that set out some of the tolerances possible in student responses to an open-ended task. Transcript analysis further identifies negotiative foci which characterize student interaction with open-ended tasks, suggesting entry points for teacher instructional intervention.

When examining the student transcripts in terms of the negotiation of meaning, the foci of their negotiations became more apparent. Our transcript analysis suggests that meaning negotiation in collaborative problem solving can be usefully distinguished at the level of the negotiative event as focusing on either sociomathematical, mathematical, or other social concerns. Consistent with the work of Yackel and Cobb (1996), students were found to engage in negotiations that relate to the mathematical aspects of the task (e.g., the calculation of the size of each room in an apartment) but also about what constitutes an acceptable approach to solving a task (e.g., the scale of the floor plan drawing). Students also had to contend with other aspects of the group work situation, such as whether someone is on task or not. We suggest that each of these foci employs its own lexicon and appeals to a distinct authority for any truth claims.

However, the negotiative events, so categorized, occur as entangled constituents of more extensive interactive episodes (e.g., the completion of an entire mathematical task). We characterize each combination of negotiative focus, lexicon and authority as a distinct negotiative mode. All three forms of sociallymediated negotiation co-exist in an entangled form in the negotiative interactions documented in the mathematics classroom. We suggest that all negotiative foci must be accommodated in a social theory of learning and each represents one avenue to improved learning outcomes in our mathematics classrooms. All three must be studied in situ and in relation to each other as they occur in authentic classroom activity. Our purpose here has been to focus on the use of open-ended tasks to stimulate student collaborative group work and create favorable conditions for the investigation of collaborative problem solving behavior.

The instructional use of open-ended tasks poses distinctive challenges for the teacher. The research reported in this paper provides a structured identification of some aspects of these challenges. The different negotiative foci identified highlight particular differences in the actions teachers might take in scaffolding students' collaborative problem solving of open-ended tasks. On the one hand, 
compared to closed tasks (that is, tasks that were not intended to offer students choice of method or answer), a high level of task open-endedness should afford greater scope and possibility for meaning negotiation. On the other hand, the negotiation in the sociomathematical and other social aspects of the tasks might be seen as a distraction from the conventional focus on developing sophisticated mathematical understanding. We suggest that such considerations (sociomathematical and other forms of social negotiation) are an inevitable consequence of the educational commitment to developing not only student mathematical understandings, but also student argumentative, problem solving and collaborative skills. Open-ended tasks such as the example used here provide a suitable instructional platform for the development of such skills.

Collaborative problem solving using open-ended tasks stimulates student negotiative interaction with a range of foci (mathematical, sociomathematical, and social). Rather than seeing these foci as in tension with each other, they represent particular aspects of student problem solving expertise in social settings, each deserving specific attention and promotion, and provide distinct entry points for teacher instructional intervention (or scaffolding) in the promotion of that expertise.

Identification of these negotiative foci of students collaboratively attempting open-ended tasks alerts teachers to instructional contingencies that might be manipulated to optimize student mathematical activity and consequent learning. Further research will examine the patterns in the alternation of the students' negotiative foci during collaborative problem solving and the association of particular patterns with successful problem solving, and possibly with valued forms of learning.

The goal of the research reported here was to better understand student collaborative activity when attempting open-ended mathematics tasks. From this we hoped to generate insight into questions of task design and deployment in the interest of promoting forms of mathematical activity (and consequent learning) that went beyond conventional mathematical understanding to include argumentative skills and skills related to functioning as a member of a collaborative group. We set out to investigate the nexus between teacher intention and student interpretation and consequent action in the instructional use of openended tasks in mathematics. The emergent distinction between the different 
negotiative foci (mathematical, sociomathematical, and social) makes visible the social dynamics of collaborative problem solving. The entanglement of these three modes of social interaction within the negotiative dialogue between students is significant if we are to understand the dynamics of collaborative problem solving and associated learning. This project envisages all three interactive modes and the associated negotiative foci as constitutive of learning and as providing distinct entry points for teacher instructional intervention.

The multiple modes of negotiative interaction highlight the considerations that students contend with during collaborative problem solving when they are attempting open-ended mathematical tasks. Whatever the teacher's instructional intentions, student task activity is shaped by these considerations. Understanding the negotiative foci of students collaboratively attempting to attempt open-ended tasks alerts teachers to instructional contingencies that might be manipulated to optimize student mathematical activity and consequent learning.

\section{Acknowledgements}

This research was conducted with Science of Learning Research Centre funding provided by the Australian Research Council Special Initiatives Grant (ARC-SR120300015). We would like to thank the students, parents, teachers, and school staff for their invaluable support of this project.

\section{References}

Australian Curriculum Assessment and Reporting Authority (2015). The Australian curriculum v7.5: Mathematics. http://v7-5.australiancurriculum.edu.au/

Binkley, M., Erstad, O., Herman, J., Raizen, S., Ripley, M., Miller-Ricci, M., et al. (2012). Defining twenty-first century skills. In P. Griffin, B. McGaw, \& E. Care (Eds.), Assessment and teaching of 21st Century skills (pp. 17-66). Dordrecht, The Netherlands: Springer.

Brousseau, G. (1986). Fondements et méthodes de la didactique des mathématiques. Recherches en didactique des mathématiques, 7(2), 33-115.

Brousseau, G., Sarrazy, B., \& Novotná, J. (2014). Didactic contract in mathematics education. In S. Lerman (Ed.), Encyclopedia of mathematics education (pp. 153-159). Dordrecht, The Netherlands: Springer.

Capar, G., \& Tarim, K. (2015). Efficacy of the cooperative learning method on mathematics achievement and attitude: A meta-analysis research. Educational Sciences: Theory and Practice, 15(2), 553-559.

Chambers, D. L. (1978). Report on the Conference on Competency Based Mathematics Education, Madison, Wisconsin, January 13, 1978. Madison, WI: Wisconsin Department of Public Instruction.

Choy, B. (2016). Snapshots of mathematics teacher noticing during task design. Mathematics Education Research Journal, 28(3), 421-440. doi:10.1007/s13394-016-0173-3

Clarke, D. J. (1996). Assessment. In A. J. Bishop, K. Clements, C. Keitel, J. Kilpatrick, \& C. Laborde (Eds.), International handbook of mathematics education (pp. 327-370). Dordrecht, The Netherlands: Kluwer Academic Publishers. 
Clarke, D. J. (Ed.). (2001a). Perspectives on practice and meaning in mathematics and science classrooms. Dordrecht, The Netherlands: Kluwer Academic Publishers.

Clarke, D. J. (2001b). Untangling uncertainty, negotiation and intersubjectivity. In D. Clarke (Ed.), Perspectives on practice and meaning in mathematics and science classrooms (pp. 33-52). Dordrecht, The Netherlands: Kluwer Academic Publishers.

Clarke, D. J. (2011). Open-ended tasks and assessment: The nettle or the rose. In B. Kaur, \& K. Y. Wong (Eds.), Assessment in the mathematics classroom (pp. 131-163). Singapore: World Scientific.

Clarke, D. J., Goos, M., \& Morony, W. (2007). Problem solving and working mathematically: An Australian perspective. ZDM-The International Journal on Mathematics Education, 39(5-6), 475-490. doi:10.1007/s11858-007-0045-0

Clarke, D. J., Keitel, C., \& Shimizu, Y. (Eds.). (2006). Mathematics classrooms in twelve countries: The insider's perspective. Rotterdam, The Netherlands: Sense Publishers.

Clarke, D. J., Strømskag, H., Johnson, H. L., Bikner-Ahsbahs, A., \& Gardner, K. (2014). Mathematical tasks and the student. In P. Liljedahl, C. Nicol, S. Oesterle, \& D. Allan (Eds.), Proceedings of the 38th conference of the International Group for Psychology of Mathematics Education and the 36th conference of the North American chapter of the Psychology of Mathematics Education (Vol. 1, pp. 117-143). Vancouver, Canada: The International Group for the Psychology of Mathematics Education.

Clarke, D. J., \& Sullivan, P. (1990). Is a question the best answer? Australian Mathematics Teacher, 46(3), 30-33.

Clarke, D. J., \& Sullivan, P. (1992). Responses to open-ended tasks in mathematics: Characteristics and implications. In W. Geeslin, \& K. Graham (Eds.), Proceedings of the $16^{\text {th }}$ Conference of the International Group for the Psychology of Mathematics Education (Vol. 1, pp. 137-144). Durham, NH.

Clarke, D. J., Xu, L. H., Arnold, J., Seah, L. H., Hart, C., Tytler, R., et al. (2012). Multi-theoretic approaches to understanding the science classroom. In C. Bruguière, A. Tiberghien, \& P. Clément (Eds.), E-Book proceedings of the ESERA 2011 biennial conference: Part 3 (pp. 26-40). Lyon, France: European Science Education Research Association.

Collet, C., \& Hine, D. (2010, Preparing graduates for both academia and industry. Australian Society for Medical Research (ASMR) Newsletter, p. 2.

CREA [Centre of Research in Theories and Practices that Overcome Inequalities] (2012). INCLUD-ED Strategies for inclusion and social cohesion in Europe from education: Final report. Spain: CREA, University of Barcelona.

Deming, D. J. (2015). The growing importance of social skills in the labor market. Cambridge, MA: National Bureau of Economic Research.

Goos, M., \& Galbraith, P. (1996). Do it this way! Metacognitive strategies in collaborative mathematical problem solving. Educational Studies in Mathematics, 30(3), 229-260.

Griffin, P. E., McGaw, B., \& Care, E. (Eds.). (2012). Assessment and teaching of 21 st century skills. Dordrecht, The Netherlands: Springer.

Hmelo-Silver, C. E., Chinn, C. A., Chan, C. K. K., \& O'Donnell, A. (Eds.). (2013). The international handbook of collaborative learning. New York: Routledge.

Hummers-Pradier, E., Beyer, M., Chevallier, P., Eilat-Tsanani, S., Lionis, C., Peremans, L., et al. (2010). Series: The research agenda for general practice/family medicine and primary health care in Europe. Part 4. Results: specific problem solving skills. The European Journal Of General Practice, 16(3), 174-181. doi:10.3109/13814788.2010.504982

Inoue, N., \& Buczynski, S. (2011). You asked open-ended questions, now what? Understanding the nature of stumbling blocks in teaching inquiry lessons. Mathematics Educator, 20(2), 10-23.

Kosyvas, G. (2016). Levels of arithmetic reasoning in solving an open-ended problem. International Journal of Mathematical Education in Science and Technology, 47(3), 356-372. doi:10.1080/0020739x.2015.1072880

Langley, P., \& Trivedi, N. (2013). Elaborations on a theory of human problem solving. Advances in Cognitive Systems, 3, 1-12.

Lave, J., \& Wenger, E. (1991). Situated learning: Legitimate peripheral participation. Cambridge, England: Cambridge University Press.

Mackay, D., Thompson, B., \& Schaub, P. (1970). Breakthrough to literacy: Teacher's manual: The theory and practice of teaching initial reading and writing. London: Longman for the Schools Council. 
Marriott, P. (1976). Two hundred ways to subtract - most of them wrong. Paper submitted as part of the course requirements of the Bachelor of Special Education. Clayton, Victoria, Australia: Monash University.

National Research Council (2011). Assessing 21st Century skills: Summary of a workshop. Washington, DC: National Academy Press.

Newell, A., \& Simon, H. A. (1972). Human problem solving. Englewood Cliffs, NJ: Prentice-Hall.

Nohda, N. (2000). Teaching by open-approach method in Japanese mathematics classroom. In T. Nakahara, \& M. Koyama (Eds.), Proceedings of the 24th Conference of the International Group for the Psychology of Mathematics Education (PME) (Vol. 1, pp. 39-53). Hiroshima, Japan.

OEDC [Organisation for Economic Co-operation and Development] (2013a). PISA 2012 results: Creative problem solving: Students'skills in tackling real-life problems (Vol. V). Paris: Author.

OECD [Organisation for Economic Co-operation and Development] (2013b). PISA 2015 draft collaborative problem solving framework. Paris: Author.

Office of the Chief Scientist (2014). Science, technology, engineering and mathematics: Australia's future. Canberra, ACT: Australian Government.

Olive, J., \& Steffe, L. P. (1990). Constructing fractions in computer microworlds. In G. Booker, P. Cobb, \& T. N. de Mendicuti (Eds.), Proceedings of the $14^{\text {th }}$ annual conference of the International Group for the Psychology of Mathematics Education, with the North American Chapter (12th PME-NA Conference) (Vol. 3, pp. 59-66). Mexico: International Group for the Psychology of Mathematics Education.

Pazos, P., Micari, M., \& Light, G. (2010). Developing an instrument to characterise peer-led groups in collaborative learning environments: Assessing problem-solving approach and group interaction. Assessment and Evaluation in Higher Education, 35(2), 191208. doi:10.1080/02602930802691572

Pólya, G. (1971). How to solve it: A new aspect of mathematical method (2nd ed.). Princeton, NJ: Princeton University Press.

Prediger, S., Clarkson, P., \& Boses, A. (2016). Purposefully relating multilingual registers: Building theory and teaching strategies for bilingual learners based on an integration of three traditions. In R. Barwell, P. Clarkson, A. Halai, M. Kazima, J. Moschkovich, $\mathrm{N}$. Planas, et al. (Eds.), Mathematics education and language diversity: The 21st ICMI Study (pp. 193-215). Cham, Switzerland: Springer International Publishing.

Remedios, L., Clarke, D. J., \& Hawthorne, L. (2008). The silent participant in small group collaborative learning contexts. Active Learning in Higher Education, 9(3), 201-216. doi:10.1177/1469787408095846

Roche, A., Clarke, D. M., Clarke, D. J., \& Sullivan, P. (2014). Primary teachers' written unit plans in mathematics and their perceptions of essential elements of these. Mathematics Education Research Journal, 26(4), 853-870. doi:10.1007/s13394-014-0130-y

Schuster, K., Plumanns, L., Groß, K., Vossen, R., Richert, A., \& Jeschke, S. (2015). Preparing for Industry 4.0 - Testing collaborative virtual learning environments with students and professional trainers. International Journal of Advanced Corporate Learning, 8(4), 14-20. doi:10.3991/ijac.v8i4.4911

Shimizu, Y., Kaur, B., Huang, R., \& Clarke, D. (Eds.). (2010). Mathematical tasks in classrooms around the world. Rotterdam, The Netherlands: Sense Publishers.

Stacey, K. (2005). The place of problem solving in contemporary mathematics curriculum documents. The Journal of Mathematical Behavior, 24(3, ̈̈i4), 341-350. doi:10.1016/j.jmathb.2005.09.004

Steffe, L. P., \& Wiegel, H. G. (1994). Cognitive play and mathematical learning in computer microworlds. Educational Studies in Mathematics, 26(2/3), 111-134.

Stein, M. K., \& Lane, S. (1996). Instructional tasks and the development of student capacity to think and reason: An analysis of the relationship between teaching and learning in a reform mathematics project. Educational Research and Evaluation, 2(1), 50-80. doi:10.1080/1380361960020103

Sullivan, P., \& Clarke, D. J. (1988). Asking better questions. Journal of Science and Mathematics Education in South East Asia, 11, 14-19.

Sullivan, P., \& Clarke, D. J. (1991). Catering to all abilities through "good" questions. The Arithmetic Teacher, 39(2), 14-18. doi:10.2307/41194944

Sullivan, P., \& Clarke, D. J. (1992). Problem solving with conventional mathematics content: Responses of pupils to open mathematical tasks. Mathematics Education Research Journal, 4(1), 42-60. doi:10.1007/bf03217231 
Sullivan, P., Knott, L., \& Yang, Y. (2015). The relationships between task design, anticipated pedagogies, and student learning. In A. Watson, \& M. Ohtani (Eds.), Task Design In Mathematics Education: An ICMI study 22 (pp. 83-114). Cham, Switzerland: Springer International Publishing.

Sullivan, P., Warren, E., \& White, P. (2000). Students' responses to content specific open-ended mathematical tasks. Mathematics Education Research Journal, 12(1), 2-17. doi:10.1007/bf03217071

Thomas, P. V., \& Higbee, J. (1996). Enhancing mathematics achievement through collaborative problem solving. Learning Assistance Review, 1(1), 38-46.

Victorian Curriculum Assessment Authority (2016). Australian Victorian Essential Learning Standards (AusVELS). http://pandora.nla.gov.au/pan/129125/201212060015/ausvels.vcaa.vic.edu.au/index.html

Viseu, F., \& Oliveira, I. B. (2012). Open-ended tasks in the promotion of classroom communication in mathematics. International Electronic Journal of Elementary Education, 4(2), 287-300.

Webb, N. M. (1991). Task-related verbal interaction and mathematics learning in small groups. Journal for Research in Mathematics Education, 22(5), 366-389. doi:10.2307/749186

Williams, G. (2000). Collaborative problem solving and discovered complexity In J. Bana, \& A. Chapman (Eds.), Proceedings of the Mathematics Education Research Group of Australasia (pp. 656-663). Freemantle, Western Australia: Mathematics Education Research Group of Australasia.

World Economic Forum (2014). Matching skills and labour market needs building social partnerships for better skills and better jobs. Cologny/Geneva, Switzerland: Author.

$\mathrm{Wu}, \mathrm{H}$. (1994). The role of open-ended problems in mathematics education. The Journal of Mathematical Behavior, 13(1), 115-128. doi:10.1016/0732-3123(94)90044-2

Yackel, E., \& Cobb, P. (1996). Sociomathematical norms, argumentation, and autonomy in mathematics. Journal for Research in Mathematics Education, 27(4), 458-477. doi:10.2307/749877 


\section{University Library}

\section{- M M N E R VA A gateway to Melbourne's research publications}

Minerva Access is the Institutional Repository of The University of Melbourne

Author/s:

Chan, MCE;Clarke, D

Title:

Structured affordances in the use of open-ended tasks to facilitate collaborative problem solving

Date:

2017-11-01

Citation:

Chan, M. C. E. \& Clarke, D. (2017). Structured affordances in the use of open-ended tasks to facilitate collaborative problem solving. ZDM-MATHEMATICS EDUCATION, 49 (6), pp.951-963. https://doi.org/10.1007/s11858-017-0876-2.

Persistent Link:

http://hdl.handle.net/11343/282677 